\title{
Abordagem intersetorial nos serviços de atenção em saúde mental
}
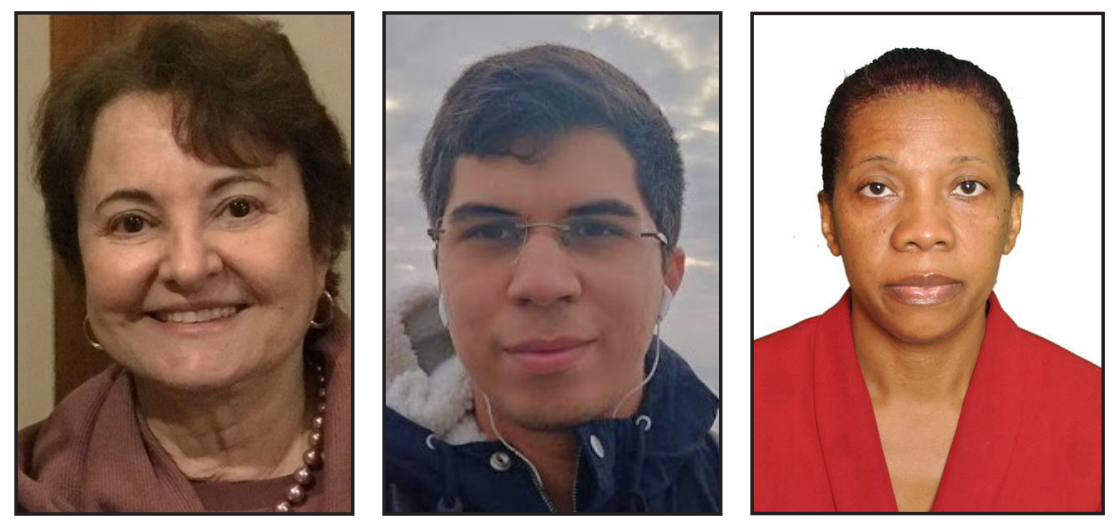

Atribui-se às doenças crônicas não transmissíveis um dos maiores desafios em saúde global, uma vez que elas abarcam as mais variadas condições crônicas que afetam a saúde e o bem-estar físico, social e mental das populações, causando sofrimento: dentre elas destacam-se as doenças mentais.

Muitas vezes não compreendidas, estigmatizadas e marginalizadas, as pessoas afetadas por problemas de saúde mental demandam proteção e amparo de políticas e estratégias que envolvam tratamento, suporte social e, principalmente, reinserção na comunidade e para tanto, é imperioso que conceitos equivocados na sociedade sejam modificados. O sucesso desse empreendimento implica na atenção a alguns elementos-chave, ou seja, o envolvimento da família e comunidade nos propósitos e medidas de cuidado, tratamento, inclusão e integração desses sujeitos nos diversos âmbitos sociais.

Líderes mundiais declararam em 2015 a saúde mental, o bem-estar, a prevenção e tratamento do abuso de substâncias psicoativas, como prioridades de saúde dentro da agenda de desenvolvimento global. Essa decisão foi crucial para um impacto positivo na vida de milhões de pessoas que precisam de ajuda para superar sua condição de dependência, ou de convivência com familiar nessas situações. A decisão de incluir a Saúde Mental como parte de 3 metas que compõem os 17 Objetivos de Desenvolvimento Sustentável (ODS) é simbólica e representativa do reconhecimento de sua importância(1).

Em 2011 a Organização Mundial da Saúde (OMS) advertiu para a complexa rede de determinantes que se relacionam e influenciam a saúde e a qualidade de vida das pessoas, alertando que o setor saúde isoladamente, não pode responder pela diversidade de fatores inter-relacionados, (culturais, sociais, econômicos e ambientais) que tem repercussões sobre a saúde das pessoas. Frente a esse reconhecimento, instou os estados-membros a um chamado intersetorial para ação, com envolvimento e compromisso ativo em prol da meta de oferecer saúde e bem-estar para toda a população(2).

Quarenta anos nos separam da criação do conceito de intersetorialidade nas ações coordenadas para melhorar a saúde: em 1978, a Declaração de Alma-Ata reconheceu o benefício do desenvolvimento econômico e social para a saúde. Na definição dos cuidados primários de saúde, a referida Declaração apontou claramente o papel dos diferentes setores, tanto em nível nacional como local, ao mesmo tempo em que apelava para uma ação intersetorial coordenada(3). 
A lógica que gerou o renascimento da abordagem ampliada de saúde pública está associada à evidências emergentes, que revelaram o papel fundamental que os fatores socioeconômicos desempenham na determinação do estado de saúde. A saúde mental não é exceção, já que constitui, juntamente com a saúde física, a dupla vertente indissociável da saúde.

Em resposta a esse novo chamado à ação, a cooperação técnica da OMS concentrou-se na melhoria da assistência à saúde mental de qualidade, por meio de um modelo comunitário e abrangente de serviços de saúde mental, em vez do tradicional modelo de hospital asilar.

No modelo de saúde mental baseado na comunidade, muda o foco da atenção, voltando-se para a Integração dos cuidados de saúde mental no sistema de atenção primária à saúde, inclusive a reabilitação na comunidade de pacientes internados em hospitais de longa permanência; a implementação de programas anti-estigma para comunidades é estimulada, bem como o desenvolvimento de intervenções preventivas efetivas baseadas na população. Destaque-se ainda o respeito ás pessoas com transtornos mentais como sujeitos com direito à voz através da plena garantia de participação e integração dentro da comunidade.

Algumas das principais recomendações compartilhadas na conclusão das atividades incluem desde o estabelecimento de uma Reforma Psiquiátrica (em 1970)(4), até as Conferencias Nacionais de Saúde Mental (em 2010) que ocorreram nos anos dois mil, as quais destacaram a importância de investimentos intersetoriais com a educação, serviço social, legislativo e sociedade civi( ${ }^{(5)}$.

Uma revisão de artigos realizada recentemente ${ }^{(6)}$ traz um elenco abrangente de planos de ação para melhorar e facilitar ações intersetoriais em diferentes níveis (contexto político e social, estruturas e ações de governança e liderança e capacitação). Recomendações assinaladas nesse trabalho envolvem, várias possibilidades de ação as quais são sumarizadas na seqüencia e das quais se destacam algumas que parecem ser centrais: o incremento da conscientização sobre os determinantes sociais da saúde para promover a sua ampla compreensão;o uso de mecanismos de financiamento e orçamento para o apoio à ação intersetorial (nesse item é prioritário a definição de metas e objetivos claros e mensuráveis); a pressão pública e eleitoral para moldar a agenda política com ênfase na ação intersetorial para a saúde e ter uma visão sobre os resultados de políticas de longo prazo no contexto de desenvolvimento sustentável. Isso certamente pressupõe o estabelecimento de mecanismos permanentes de governança intersetorial. E a promoção de liderança e gestão efetivas e eficazes.

O engajamento da sociedade civil e outras partes interessadas (como grupos de apoio da sociedade civil) é apontado como de relevância nesse processo. Envolver a mídia local e nacional para relatar e disseminar as iniciativas intersetoriais bem sucedidas é um procedimento estratégico que pode promover e facilitar essas ações.

É salientado ainda, no trabalho mencionado, a importância de Identificar oportunidades que podem permitir o avanço das políticas intersetoriais para a saúde (por exemplo, uma mudança de governo) especificamente no âmbito da saúde mental.Também se destaca a necessidade de ampliar as capacidades do setor de saúde para atuar no nível das relações (por exemplo, habilidades de negociação e resolução de conflitos), bem como a vinculação de metas de saúde mental a outro processos e empreendimentos já existentes, por exemplo, estratégias nacionais em setores não relacionados estritamente,à saúde.

Conforme exposto, órgãos internacionais de saúde e especialistas expõem anseios e a recomendação de iniciativas e empreendimentos que se situam num continuum que inclui desde ações mais simples até as de grande complexidade, por envolverem não só os profissionais de saúde, mas uma diversidade de atores sociais.

Por outro lado, há necessidade de se obter mais evidências sobre as ações intersetoriais, de modo que se possa alcançar melhor compreensão dos fenômenos ocasionados pelas mais variadas transições de cunho econômico, social, cultural, tecnológico e espiritual que afetam as sociedades de maneira local e global. A partir disso poder-se-á estabelecer estratégias que melhor contribuam para harmonização dos serviços de saúde com as comunidades e os ambientes próximos ao enfermo mental. 


\section{Referências}

1. World Health Organization. Mental health included in the UN sustainable development goals. Washington: WHO; 2016.

2. World Health Organization. Intersectoral Action on Health: A path for policy-makers to implement effective and sustainable action on health. Washington: WHO; 2011.

3. World Health Organization. Declaration of Alma Ata. In: International Conference on Primary Health Care, Alma-Ata, USSR, 6-12 Sept 1978. [cited Oct 1, 2016]. Available from: http://www.who.int/publications/almaata_declaration_en.pdf 4. Scheffer G, Silva LG. Saúde mental, intersetorialidade e questão social: um estudo na ótica dos sujeitos. Serv Soc Soc. 2014;(118):366-93. Disponível em: http://www.scielo.br/pdf/sssoc/n118/a08n118.pdf

5. Olschowsky A, Wetzel C, Schneider JF, Pinho LB, Camatta MW. Avaliação das parcerias intersetoriais em saúde mental na estratégia saúde da família. Texto Contexto-Enferm. 2014; 23(3):591-9.

6. Mikkonen JP. Intersectoral Action for Health: Challenges, Opportunities, and Future Directions in the WHO European Region. [Dissertation]. Toronto (CA): York University; 2018. [cited Nov 19, 2018]. Available from: https://yorkspace. library.yorku.ca/xmlui/bitstream/handle/10315/35018/Mikkonen_Juha_2018_PhD.pdf?sequence=2\&isAllowed=y

\footnotetext{
${ }^{1}$ Isabel Amélia Costa Mendes

PhD, Professora Emérita, Professor Titular Sênior, Universidade de São Paulo, Escola de Enfermagem de Ribeirão Preto, Centro Colaborador da OPAS/OMS para o Desenvolvimento da Pesquisa em Enfermagem, Brasil.

E-mail: iamendes@eerp.usp.br

(D) https://orcid.org/0000-0002-0704-4319

${ }^{2}$ Artur Acelino Francisco Luz Nunes Queiroz

Doutorando, Universidade de São Paulo, Escola de Enfermagem de Ribeirão Preto, Centro Colaborador da OPAS/ OMS para o Desenvolvimento da Pesquisa em Enfermagem, Brasil.

(D) https://orcid.org/0000-0002-6350-1908

\section{${ }^{3}$ Karen Roberts}

Doutoranda, Universidade de São Paulo, Escola de Enfermagem de Ribeirão Preto, Centro Colaborador da OPAS/ OMS para o Desenvolvimento da Pesquisa em Enfermagem, Brasil.
} 